\title{
Heavy sulphur compounds, higher alcohols and esters production profile of Hanseniaspora uvarum and Hanseniaspora guilliermondii grown as pure and mixed cultures in grape must
}

\author{
N. Moreira, F. Mendes, P. Guedes de Pinho, T. Hogg, I. Vasconcelos* \\ Escola Superior de Biotecnologia, Universidade Católica Portuguesa, Rua Dr. António Bernardino de Almeida, 4200-072, Porto, Portugal
}

\begin{abstract}
Hanseniaspora guilliermondii and Hanseniaspora uvarum were tested in grape must fermentations as pure and mixed starter cultures with Saccharomyces cerevisiae. In pure cultures, the specific growth rates found were $0.29 \mathrm{~h}^{-1}$ for H. uvarum, $0.23 \mathrm{~h}^{-1}$ for H. guilliermondii and $0.18 \mathrm{~h}^{-1}$ for S. cerevisiae. No significant differences were observed between these values and those obtained in mixed cultures. Results presented in this work show that growth of apiculate yeasts during the first days of fermentation enhances the production of desirable compounds, such as esters, and may not have a negative influence on the production of higher alcohols and undesirable heavy sulphur compounds. Growth of apiculate yeasts reduced the total content of higher alcohols in wines, when compared to those produced by a pure culture of $S$. cerevisiae. Furthermore, the highest levels of 2-phenylethyl acetate were obtained when $H$. guilliermondii was inoculated in grape musts, whereas $H$. uvarum increased the isoamyl acetate content of wines. Apiculate yeasts produced high amounts of ethyl acetate; however, the level of this compound decreased in mixed cultures of apiculate yeasts and $S$. cerevisiae. When S. cerevisiae was used as a starter culture, wines showed higher concentrations of glycerol, 2phenylethanol and ethyl hexanoate. In mixed cultures of apiculate yeasts and S. cerevisiae, wines presented amounts of methionol, acetic acid-3-(methylthio)propyl ester, 4-(methylthio)-1-butanol, 2-mercaptoethanol and cis-2-methyltetrahydro-thiophen-3-ol similar to those produced by a pure culture of S. cerevisiae. An increase in the amounts of 3-(ethylthio)-1-propanol, trans-2-methyltetrahydro-thiophen-3-ol and 3mercapto-1-propanol was obtained in wines produced from mixed cultures with $\mathrm{H}$. guilliermondii.
\end{abstract}

Keywords: $\mathrm{H}$ anseniaspora guilliermondii; $\mathrm{H}$ anseniaspora uvarum; Saccharomyces cerevisiae; W ine volatile composition; $\mathrm{H}$ eavy sul phur compounds

\section{Introduction}

The trend in winemaking is using starter cultures of $S$. cerevisiae, to induce reliable and rapid fermentation, resulting in a wine of consistent quality. Despite of the advantages of commercial cultures, regarding the easy control and homogeneity of fermentations, strains which are more specific and appropriate to the individual characteristics of particular wines should be selected (Lambrechts and Pretorius, 2000; Ribéreau-Gayon et al., 2000; Romano et al., 2003). Furthermore, wine is the result of the interaction of different yeast species, in particular between non-Saccharomyces yeasts from the early fermentation phase and Saccharomyces spp. Many authors claim that the contribution of non-Saccharomyces yeasts cannot be negligible and their use in mixed starter cultures may lead to wine characterised by a more complex and better aroma (Fleet and Heard, 1993; Henick-Kling et al., 1998; Lambrechts and Pretorius, 2000; Romano et al., 2003). Henick-Kling et al. (1998) showed, through sensory evaluation of Riesling wines, that the largest differences among wines were attributed to whether they were produced by an un-inoculated fermentation or by a

\footnotetext{
* Corresponding author. Tel.: +351 22 5580049; fax: +351 225090351.
} E-mail address: ivasconcelos@esb.ucp.pt (I. Vasconcelos). starter culture. Higher scores for typical 'fruity' descriptors (spice, apple, melon and pear) were all seen in the un-inoculated wines, while the inoculated wines had higher scores for unfavourable descriptors.

In musts, non-Saccharomyces yeasts (Hanseniaspora uvarum and Hanseniaspora guilliermondii) were found at high cell densities, up to $10^{6}-10^{8}$ cells $\mathrm{ml}^{-1}$, during the first 4-6 days of fermentation, until an ethanol level of approximately 4-7\% $\left(\mathrm{v} \mathrm{v}^{-1}\right)$ was obtained; however, ethanol contents of 9.6\% $\left(\mathrm{v} \mathrm{v}^{-1}\right)$ and $9.9 \%\left(\mathrm{v} \mathrm{v}^{-1}\right)$ were obtained in wines produced by inoculation of pure cultures of $H$. guilliermondii and $H$. uvarum respectively, showing that some strains produce higher ethanol concentrations than previously thought (Schütz and Gafner, 1993; Rojas et al., 2003). Other indigenous yeasts found in grapes include members of genera Metschnikowia, Candida, Debaryomyces, Torulaspora, Pichia, Brettanomyces (Dekkera), Kluyveromyces, Cryptococcus, Rhodotorula, Saccharomycodes, Schizosaccharomyces and Zygosaccharomyces. After the early fermentation phase, S. cerevisiae, with a higher ethanol tolerance, becomes dominant and keeps its activity until the end of fermentation (Kunkee, 1984; Fleet, 2003; Romano et al., 2003; Xufre et al., 2006). Besides ethanol concentration, the occurrence and growth of non-Saccharomyces yeasts during alcoholic fermentation is also influenced by the diversity of yeast population in grape musts, the interaction between the different yeast species and strains, the nu- 
trient composition of grape musts, and the processing conditions, mainly sulphur dioxide addition and fermentation temperature (Fleet and Heard, 1993; Lema et al., 1996; Schütz and Gafner, 1993; Fleet, 2003; Nissen and Arneborg, 2003; Nissen et al., 2003; Pérez-Nevado et al., 2006).

Experiments performed by pure, mixed or sequential cultures of apiculate yeasts with $S$. cerevisiae strains in grape must showed that there were significant differences in the chemical composition of resulting wines (Herraiz et al., 1990; Ciani and Picciotti, 1995; Gil et al., 1996; Lambrechts and Pretorius, 2000; Rojas et al., 2003; Romano et al., 2003). However, there is considerable controversy concerning the effect of growth of apiculate yeasts on the organoleptic quality of wines. Ciani and Picciotti (1995) excluded the possibility of using apiculate yeasts in winemaking, due to the production of large amounts of ethyl acetate and acetic acid. Grape musts fermentations performed by Gil et al. (1996) showed that H. uvarum and K. apiculata were the main producers of higher alcohols. However, Romano et al. (2003) reported that apiculate yeasts were low producers of higher alcohols, when compared to S. cerevisiae. Herraiz et al. (1990) found a higher concentration of isoamyl alcohols and esters in wines fermented by Saccharomyces spp. than in those fermented by pure cultures of apiculate yeasts. Nevertheless, Rojas et al. (2003) showed that $H$. guilliermondii 11104 (CECT, Spain) promote the esterification of various alcohols such as ethanol, geraniol, isoamyl alcohols and 2-phenylethanol.

The volatile sulphur compounds in wines come mainly from the metabolism of yeast and have a significant role in the flavour of wines.
They contribute mainly to unpleasant aromas even at low concentrations, being related to many organoleptic defects of wines, well-known as sulphur dioxide odour or reduced character (Anocibar Beloqui and Bertrand, 1995; Mestres et al., 2000). The flavour of these compounds can be described with terms such as potato, cauliflower, cabbage, garlic, boxer and poultry, among others, which allude to their negative effects on wine aroma (Rapp et al., 1985; Rauhut, 1993; Anocibar Beloqui and Bertrand, 1995; Lavigne, 1996; Darriet et al., 1999; Mestres et al., 2000). The less volatile sulphur compounds cannot be eliminated by normal wine practices, such as racking and aeration, due their high boiling point (Ribéreau-Gayon et al., 2000). Heavy sulphur compounds production by non-Saccharomyces yeasts is not well-documented in literature and it is important to evaluate how these species contribute, during the early stages of fermentation, to the sulphur compounds profile of wines.

Mechanisms of heavy sulphur compounds synthesis by yeast are still not well-known. In general, grape must is deficient in organic sulphur compounds, such as cysteine, gluthathione and methionine, and this may lead the yeast to synthesise these compounds, activating the sulphate reduction sequence (SRS) pathway (Rauhut, 1993; Wang et al., 2003; Swiegers and Pretorius, 2007). In this pathway (Fig. 1), the sulphate molecule is reduced to sulphide which, in turn, is incorporated into amino acids precursors, $O$-acetylserine or 0 -acetylhomoserine, yielding methionine and cysteine. When amino acid precursors become depleted within the cell, as a result of a lack of pantothenic acid, $\mathrm{H}_{2} \mathrm{~S}$ is liberated (Wang et al., 2003; Swiegers et al., 2005). Sulphur

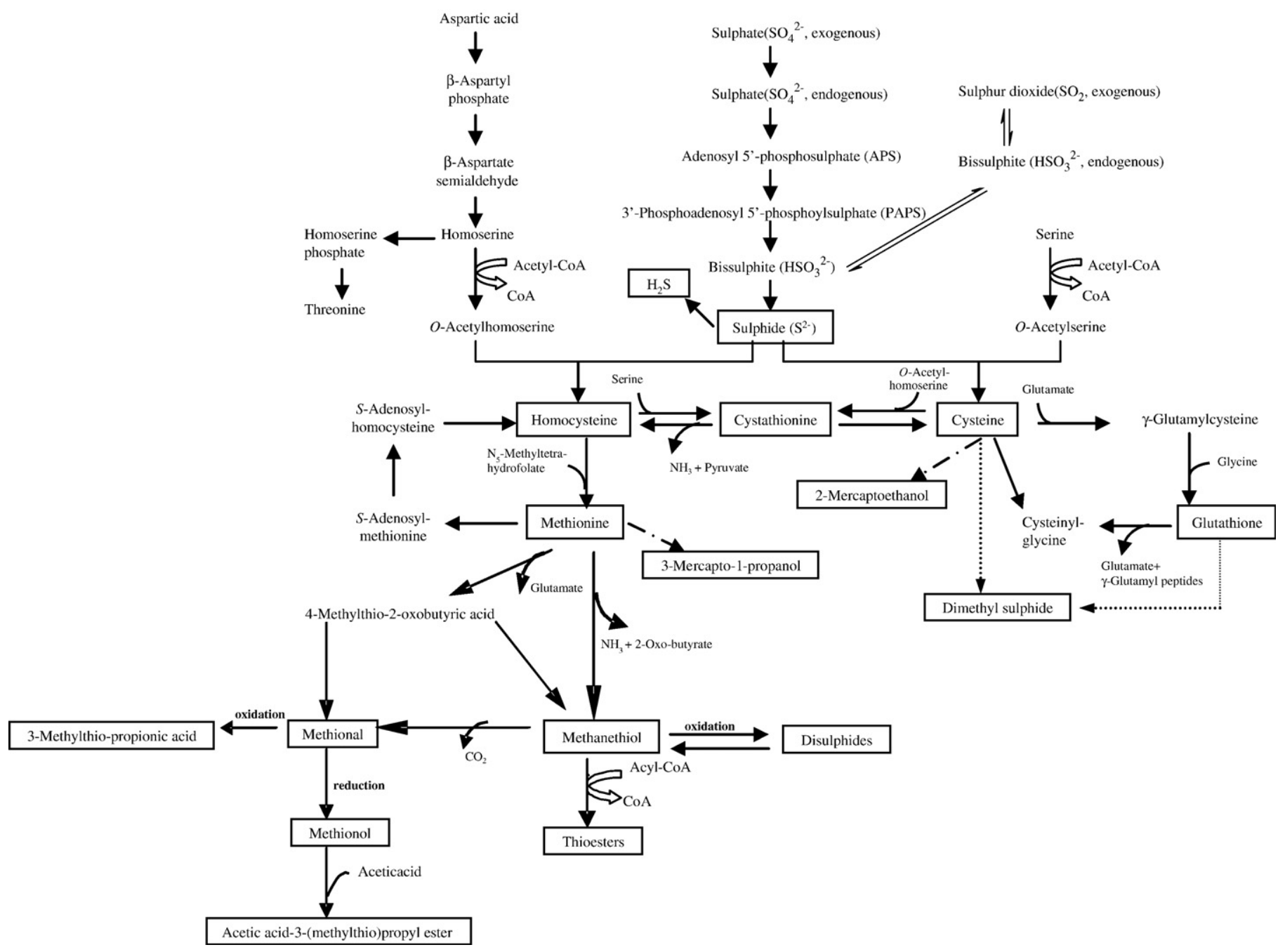

Fig. 1. Yeast sulphur metabolism based on Rauhut (1993), Wang et al. (2003) and Landaud et al. (2008). 
amino acids and precursors mediate the production of organic sulphur compounds in wines, via the Ehrlich reaction. The metabolic pathway for 3-(methylthio)-1-propanol (methionol) synthesis is well-known; this compound is produced by yeast from methionine, via deamination, followed by decarboxylation; the aldehyde thus formed, 3(methylthio)-1-propanal (methional), is then reduced to the alcohol (methionol) or oxidised to the acid (3-methylthio-propionic acid). The reaction of methionol with acetic acid yields acetic acid-3-(methylthio)propyl ester (Rauhut, 1993). The biosynthesis of 3-mercapto-1propanol from methionine and 2-mercaptoethanol from cysteine were also proposed and seem to be similar to the methionol metabolic pathway (Mestres et al., 2000; Landaud et al., 2008). The high volatile sulphur compound, methanethiol, can be synthesised from methionine; this compound may be oxidised to disulphides, like dimethyl disulphide, or may lead, via acyl-CoA, to the production of thioesters, such as $S$-methylthioacetate and $S$-ethylthioacetate. Dimethyl sulphide may also be synthesised from cysteine, cystine or glutathione (Swiegers et al., 2005; Landaud et al., 2008).

In order to understand the effect of growth of apiculate yeasts on the final composition of wines, in terms of desirable and undesirable compounds, experiments were carried out using pure and mixed cultures of $H$. guilliermondii, $H$. uvarum and $S$. cerevisiae strains. The apiculate yeast strains used in this work were characterised for their heavy sulphur compounds production profile in wine must, which was never reported before. Yeasts fermentative behaviour, as well as esters and higher alcohols composition of resulting wines were also evaluated.

\section{Materials and methods}

\section{Yeast strains}

The strains used in this study were H. guilliermondii NCYC 2380 (National Collection of Yeast Cultures, Norwich, UK), H. uvarum PYCC 4193T and Saccharomyces cerevisiae PYCC 3507T (Portuguese Yeast Culture Collection, Instituto Gulbenkian da Ciência, Oeiras, Portugal). Yeasts were maintained on Yeast Malt Agar slants (YM Agar, Difco, Detroit, IN, USA).

\section{Fermentation conditions}

Grape must, from the Douro region in Portugal, was previously steam-sterilized at $90{ }^{\circ} \mathrm{C}$ for 15 min to eliminate microbiological contamination. Pure cultures of $\mathrm{H}$. guilliermondii $(\mathrm{Hg}), \mathrm{H}$. uvarum (Hu) and S. cerevisiae $(\mathrm{Sc})$ and mixed cultures (Hu-Sc, $\mathrm{Hg}-\mathrm{Sc}, \mathrm{Hu}-\mathrm{Hg}-\mathrm{Sc}$ ) were carried out in $200 \mathrm{ml}$ of must at $25^{\circ} \mathrm{C}$, under gentle agitation $(80 \mathrm{rpm})$. Each experiment was reproduced four times. Inocula of each yeast strain were previously grown at $25^{\circ} \mathrm{C}$ for $24 \mathrm{~h}$ in YM broth (Difco Laboratories, Detroit, IN, USA). The inoculation of media was carried out in order to obtain an initial cell concentration of $10^{5}-10^{6} \mathrm{cfu} \mathrm{ml}^{-1}$ of each strain.

\section{Enumeration of yeast populations}

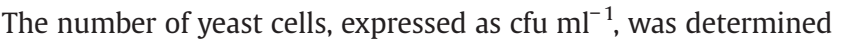
using the pour plate method, after incubation of plates at specific temperatures for $48 \mathrm{~h}$ on selective and non-selective media as described by Moreira et al. (2005).

\section{Analytical determinations}

After fermentation, yeast cells were removed by centrifugation at $8000 \mathrm{rpm}$ and $4{ }^{\circ} \mathrm{C}$ for $15 \mathrm{~min}$. The supernatant was analysed using chromatographic procedures, according to the following methods.

The concentration of ethanol, glycerol, glucose and fructose was determined by High Performance Liquid Chromatography using a
Beckman, System Gold. Separation was performed on an Aminex ${ }^{R}$ HPX-87H column $(300 \times 7.8 \mathrm{~mm}$, Bio-Rad $)$ and detection was assessed by refractive index. The mobile phase was a $0.5 \mathrm{mM}$ sulphuric acid

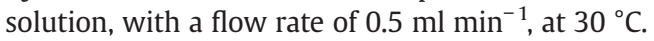

Aliphatic higher alcohols (1-propanol, 2-methyl-1-propanol, 2methyl-1-butanol and 3-methyl-1-butanol) and ethyl acetate were analysed using a Hewlett-Packard 5890 gas chromatograph equipped with a flame ionisation detector and connected to a Hewlett-Packard 3396 Integrator. $50 \mu \mathrm{l}$ of 4 -methyl-2-pentanol at $10 \mathrm{~g} \mathrm{l}^{-1}$ were added to $5 \mathrm{ml}$ of wine as internal standard. The wine $(1 \mu \mathrm{l})$ was injected (split, 1:60) into a CP-WAX $57 \mathrm{CB}$ column (Chrompack) of $50 \mathrm{~m} \times 0.25 \mathrm{~mm}$ and $0.2 \mu \mathrm{m}$ phase thickness. The temperature program was $40{ }^{\circ} \mathrm{C}(5 \mathrm{~min})$ to $180{ }^{\circ} \mathrm{C}(0 \mathrm{~min})$ at $3{ }^{\circ} \mathrm{C} \mathrm{min}^{-1}$. Injector and detector temperatures were set at $250{ }^{\circ} \mathrm{C}$. Carrier gas was $\mathrm{H}_{2}$ at $1-2 \mathrm{ml} \mathrm{min}^{-1}$.

The determination of acetates of higher alcohols (isoamyl acetate, 2-phenylethyl acetate and hexyl acetate) and ethyl esters of fatty acids (ethyl hexanoate, ethyl octanoate and ethyl decanoate) was performed in a Perkin-Elmer Autosystem gas chromatograph, equipped with a flame ionisation detector. $50 \mathrm{ml}$ of wine, with 4-decanol at $1.5 \mathrm{mg} \mathrm{l}^{-1}$ as internal standard, was extracted successively with 4,2 and $2 \mathrm{ml}$ of ether-hexane $\left(1: 1 \mathrm{v} \mathrm{v}^{-1}\right)$ for $5 \mathrm{~min}$. The organic phase $(1 \mu \mathrm{l})$ was injected (splitless, $0.3 \mathrm{~min}$ ) into a CP-WAX 58 (FFAP)-CB column (Chrompack) of $50 \mathrm{~m} \times 0.32 \mathrm{~mm}$ and $0.3 \mu \mathrm{m}$ phase thickness. Temperature program was $40{ }^{\circ} \mathrm{C}(5 \mathrm{~min})$ to $220^{\circ} \mathrm{C}(20 \mathrm{~min})$ at $2{ }^{\circ} \mathrm{C} \mathrm{min}-1$. Injector and detector temperatures were set at $250{ }^{\circ} \mathrm{C}$. The carrier gas used was $\mathrm{H}_{2}$ at $1-2 \mathrm{ml} \mathrm{min}^{-1}$.

Heavy sulphur compounds were determined according to the method described by Moreira et al. (2004). The sulphur compounds analysed were methionol (3-(methylthio)-1-propanol), 2-mercaptoethanol, 2-(methylthio)ethanol, 2-methyltetrahydrothiophen-3one, acetic acid-3-(methylthio)propyl ester, 3-mercapto-1-propanol, cis- and trans-2-methyltetrahydrothiophen-3-ol, 3-(ethylthio)-1-propanol and 4-(methylthio)-1-butanol. The concentrations of commercially available sulphur compounds were expressed as $\mu \mathrm{g} \mathrm{l}^{-1}$. For those compounds whose reference standard was not available, the amounts were expressed as the ratio of peak area/peak area of internal standard. In the analysis performed 2-(methylthio)ethanol and 2-methyltetrahydrothiophen-3-one resulted co-eluate and, consequently, a single concentration was obtained using the calibration curve of 2-methyltetrahydrothiophen-3-one.

\section{Statistical analysis}

An analysis of variance (ANOVA) was applied to the experimental data; results were considered significant if the associated $P$ value was below 0.05 . The significant differences were determined by Tukey tests. All statistical analyses were performed using the software SPSS for Windows, version 10.0.

\section{Results and discussion}

Experiments were performed in order to evaluate the fermentation kinetics and the production of higher alcohols, esters and heavy sulphur compounds by pure and mixed cultures of $H$. uvarum, $H$. guilliermondii and S. cerevisiae on grape musts.

\section{Growth behaviour of yeast strains in pure and mixed cultures}

Growth kinetics of each yeast strain, ethanol, glycerol, fructose and glucose concentrations during fermentations of pure cultures of $H$. uvarum, $H$. guilliermondii and $S$. cerevisiae in grape must are shown in Fig. 2. Apiculate yeasts presented a lag phase of approximately $4 \mathrm{~h}$ and specific growth rates of $0.29 \mathrm{~h}^{-1}$ for $H$. uvarum and $0.23 \mathrm{~h}^{-1}$ for $H$. guilliermondii (Table 1). Experiments performed with a pure culture of $S$. cerevisiae presented a different growth behaviour: the maximum viable cell number was higher than the one observed for apiculate 

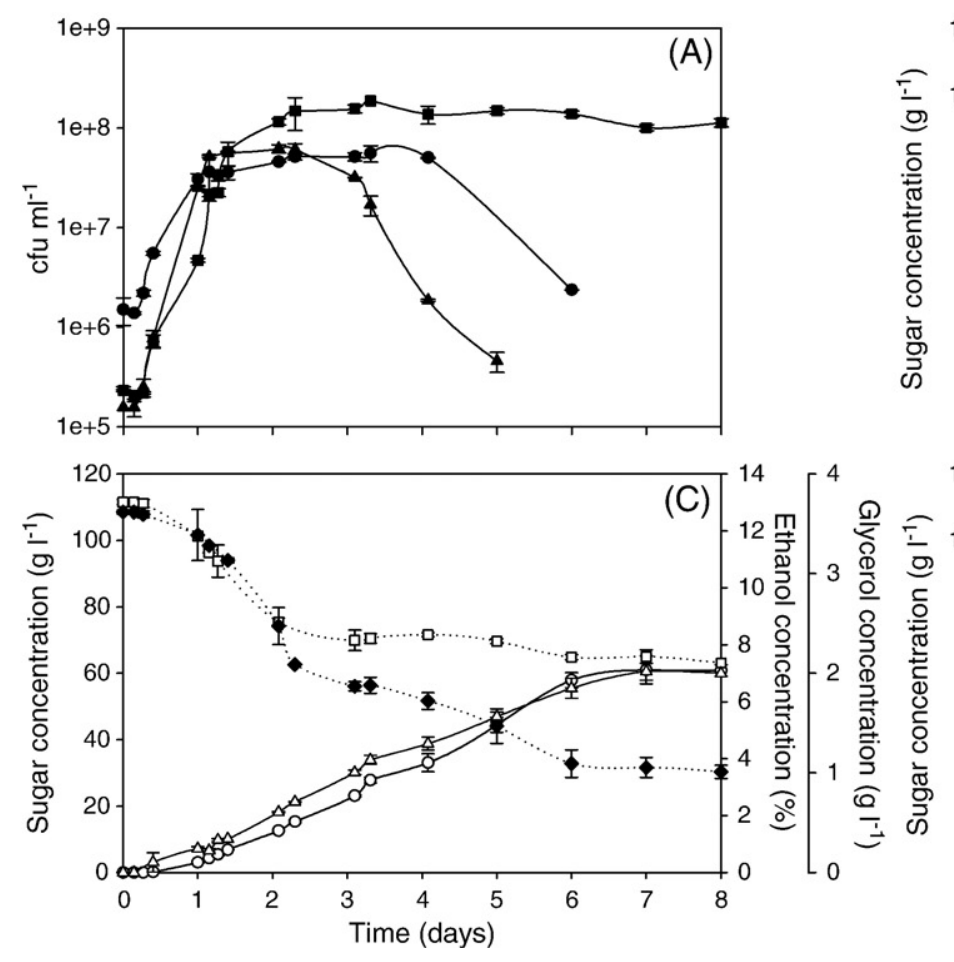
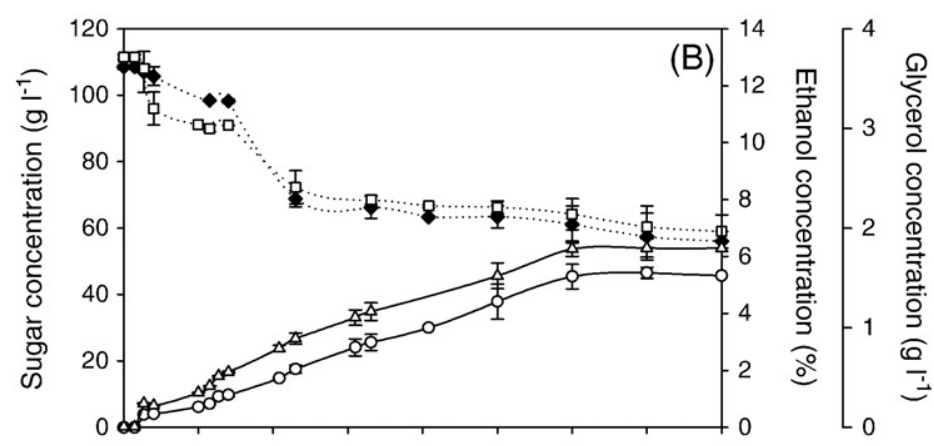

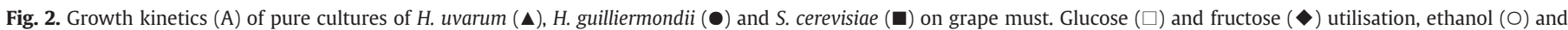

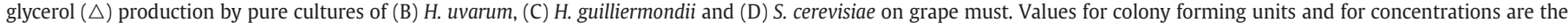
average values of results obtained from four fermentations. Vertical bars represent standard deviation.

yeasts and the specific growth rate was $0.18 \mathrm{~h}^{-1}$ (Fig. 2A). Only a few studies reported the kinetic parameters of yeast strains growth on grape musts. Ciani and Picciotti (1995), using a modified grape juice, reported specific growth rates of $0.14 \mathrm{~h}^{-1}$ for $H$. uvarum, $0.23 \mathrm{~h}^{-1}$ for $K$. apiculata and $0.26 \mathrm{~h}^{-1}$ for $S$. cerevisiae.

The fermentation was considered to be finished when the sugar content of the culture broth was constant. As expected, sugar was not completely consumed in pure cultures of Hanseniaspora strains (Fig. 2B and C). H. guilliermondii was able to consume higher amounts of sugar (127 $\mathrm{g} \mathrm{l}^{-1}$ ) than H. uvarum (105 $\mathrm{g} \mathrm{l}^{-1}$ ); these yeasts started the decline phase after four and three days of fermentation, respectively. During fermentation, $H$. uvarum presented similar depletion of glucose and fructose from the medium, resulting in a similar final consumption of glucose and fructose of $52.5 \mathrm{~g} \mathrm{l}^{-1}$. However, H. guilliermondii presented a frutophilic behaviour, consuming fructose faster than glucose; at the end of fermentation this strain consumed $78.2 \mathrm{~g} \mathrm{l}^{-1}$ of fructose and $48.5 \mathrm{~g} \mathrm{l}^{-1}$ of glucose (Fig. 2B). As expected, S. cerevisiae is glucophilic, since in the presence of similar amounts of glucose and fructose the strain consumed glucose faster than fructose. The frutophilic beha- viour of Hanseniaspora yeasts has been previously described (Ciani and Fatichenti, 1999); these authors also reported that $H$. guilliermondii was able to consume higher amounts of sugar than H. uvarum.

The maximum ethanol content of the media was $5.4 \%$ for $H$. uvarum, $7.2 \%$ for $H$. guilliermondii and $11.6 \%$ for S. cerevisiae. A higher production of glycerol was also obtained for $S$. cerevisiae $\left(3.0 \mathrm{~g} \mathrm{l}^{-1}\right)$, followed by $H$. guilliermondii $\left(1.9 \mathrm{~g} \mathrm{l}^{-1}\right)$ and $H$. uvarum $\left(1.8 \mathrm{~g} \mathrm{l}^{-1}\right)$; however, these vales are lower than those usually found in wines, between 5 and $20 \mathrm{~g} \mathrm{l}^{-1}$ (Ribéreau-Gayon et al., 2000). Glycerol brings fullness and softness to wines and reinforces the sweetness of ethanol in dry wines.

Growth kinetics of each yeast strain in mixed cultures is shown in Fig. 3; ethanol and glycerol production and fructose and glucose concentrations during fermentations are presented in Fig. 4. When used as mixed cultures, yeast strains showed growth parameters similar to those observed in pure cultures (Table 1). H. uvarum reached the stationary phase faster than $H$. guilliermondii and $S$. cerevisiae. A higher maximum viable cell number was always obtained for S. cerevisiae. Similar total sugar consumption (141 to $145 \mathrm{~g} \mathrm{l}^{-1}$ ) was

Table 1

Fermentation parameters of pure and mixed cultures of Hanseniaspora uvarum (Hu), Hanseniaspora guilliermondii (Hg) and Saccharomyces cerevisiae (Sc) in grape must

\begin{tabular}{|c|c|c|c|c|c|c|c|c|c|c|}
\hline \multirow[t]{2}{*}{ Fermentation parameters } & \multicolumn{3}{|c|}{ Pure cultures } & \multicolumn{7}{|c|}{ Mixed cultures } \\
\hline & $\mathrm{Hu}$ & $\mathrm{Hg}$ & Sc & $\mathrm{Hu}-\mathrm{Sc}$ & & $\mathrm{Hg}-\mathrm{Sc}$ & & $\mathrm{Hu}-\mathrm{Hg}-\mathrm{Sc}$ & & \\
\hline Consumed fructose $\left(\mathrm{g} \mathrm{l}^{-1}\right)$ & 52.5 & 78.2 & 66.5 & 60 & & 57 & & 61 & & \\
\hline Consumed glucose $\left(\mathrm{g} \mathrm{l}^{-1}\right)$ & 52.6 & 48.5 & 106 & 85 & & 86 & & 80 & & \\
\hline Ethanol production $\left(\%, \mathrm{v} \mathrm{v}^{-1}\right)$ & $5.4(0.1)$ & $7.2(0.2)$ & $11.6(0.3)$ & $10.0(0.3)$ & & $9.2(0.2)$ & & $9.8(0.3)$ & & \\
\hline \multirow[t]{2}{*}{ Glycerol production $\left(\mathrm{g} \mathrm{l}^{-1}\right)$} & $1.8(0.1)$ & $1.9(0.1)$ & $3.0(0.2)$ & $2.3(0.1)$ & & $2.0(0.1)$ & & $2.2(0.1)$ & & \\
\hline & & & & $\mathrm{Hu}$ & Sc & $\mathrm{Hg}$ & Sc & $\mathrm{Hu}$ & $\mathrm{Hg}$ & Sc \\
\hline$\mu_{X}\left(\mathrm{~h}^{-1}\right)$ & $0.29(0.01)$ & $0.23(0.01)$ & $0.18(0.02)$ & $0.32(0.02)$ & $0.19(0.01)$ & $0.25(0.01)$ & $0.15(0.01)$ & $0.25(0.01)$ & $0.21(0.03)$ & $0.14(0.01)$ \\
\hline
\end{tabular}

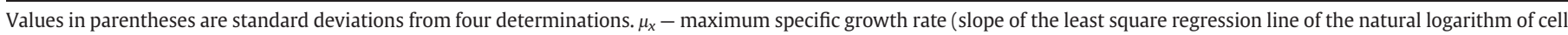
mass vs time data during the exponential growth phase). 

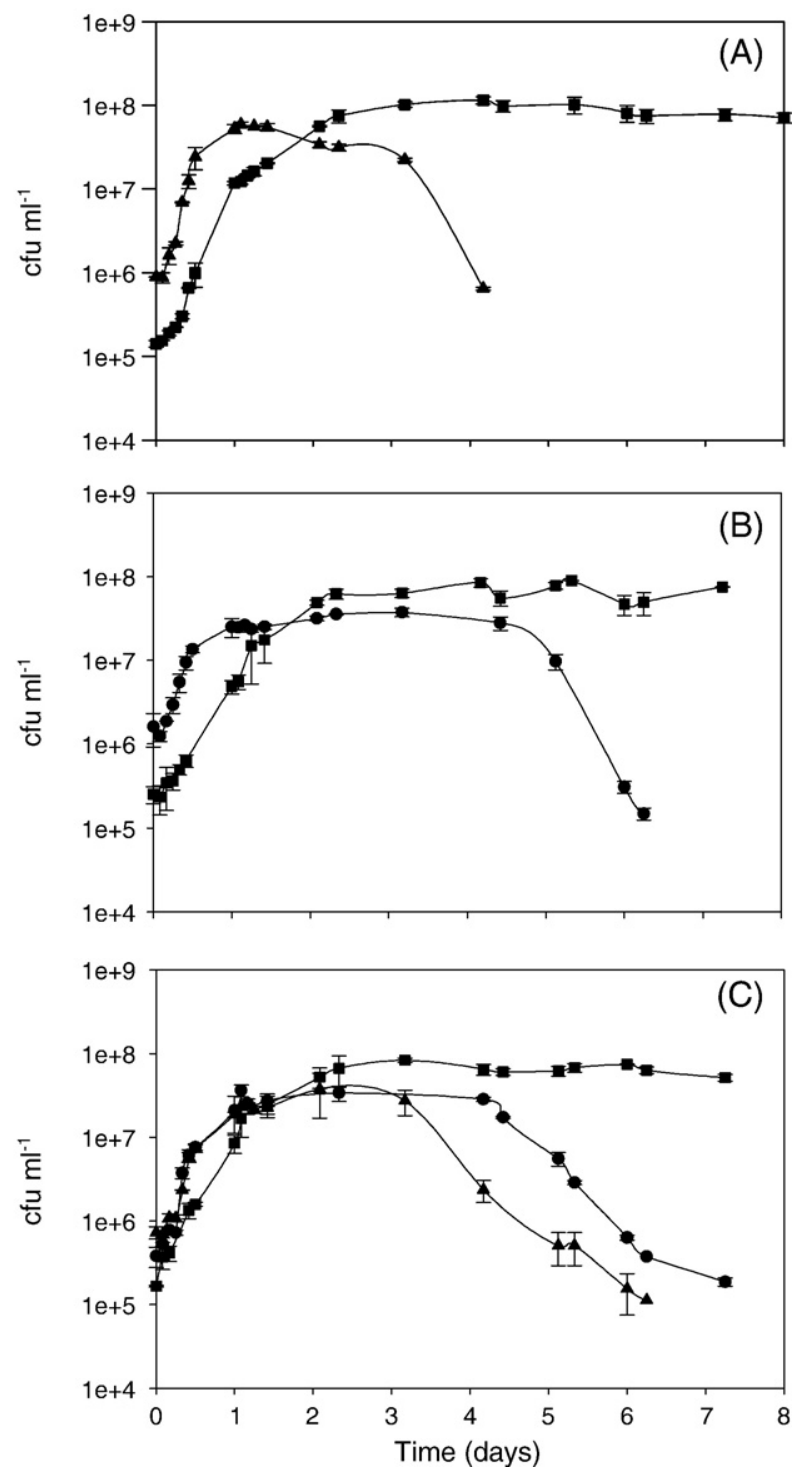

Fig. 3. Growth kinetics of mixed cultures of $H$. uvarum $(\boldsymbol{\Delta}), H$. guilliermondii $(\bullet)$ and $S$. cerevisiae (ם) on grape must. (A) H. uvarum and S. cerevisiae, (B) H. guilliermondii and $S$. cerevisiae, (C) H. uvarum, H. guilliermondii and S. cerevisiae. Values for colony forming units and for concentrations are the average values of results obtained from four fermentations. Vertical bars represent standard deviation.

found in mixed cultures of apiculate yeasts with S. cerevisiae; in these fermentations, glucose was consumed faster than fructose, showing the highest fermentative capacity of $S$. cerevisiae. Ethanol and glycerol levels obtained in mixed cultures of apiculate yeasts with $S$. cerevisiae were lower than those produced by a pure culture of $S$. cerevisiae.

As in pure cultures, when grown in mixed cultures $H$. uvarum started the decline phase for an ethanol level of approximately $5.4 \%$ $\left(\mathrm{v} \mathrm{v}^{-1}\right)$, while $H$. guilliermondii kept its activity for higher ethanol concentrations, up to $6.8 \%\left(\mathrm{v} \mathrm{v}^{-1}\right)$. The disappearance of Hanseniaspora yeasts can be associated to their weaker ethanol tolerance or to the production of other toxic compounds besides ethanol (Goto, 1980; Fleet et al., 1984; Martinez et al., 1989; Schütz and Gafner, 1993; Lema et al., 1996; Constantí et al., 1997; Egli et al., 1998; Cocolin et al., 2000; Fleet, 2003). However, some recent studies associated the early death of non-Saccharomyces yeasts during mixed fermentations to the cellcell contact-mediated mechanism which results of the high cell concentrations of S. cerevisiae yeasts (Nissen and Arneborg, 2003; Nissen et al., 2003).

\section{Composition of wines}

Higher alcohols

Pure cultures of H. uvarum and H. guilliermondii led to wines with a total content in aliphatic higher alcohols of $143 \mathrm{mg} \mathrm{l}^{-1}$ and $257 \mathrm{mg} \mathrm{l}^{-1}$ respectively (Table 2 ). These values are significantly lower than those obtained in wines produced by a pure culture of $S$. cerevisiae (574 $\mathrm{mg} \mathrm{l}^{-1}$ ); furthermore, growth of apiculate yeasts with $S$. cerevisiae decreased the total content of higher alcohols in wines. The lowest content in 1-propanol was obtained in wines produced by a pure culture of $H$. uvarum. Wines produced by pure cultures of apiculate yeasts also presented a lower content in 3-methyl-1-propanol, 2-methyl-1-butanol and 3-methyl-1-butanol than wines obtained by a pure culture of $S$. cerevisiae.

For concentrations below $300 \mathrm{mg} \mathrm{l}^{-1}$, higher alcohols contribute to the aromatic complexity of wine; however, at concentrations higher than $400 \mathrm{mg} \mathrm{l}^{-1}$ they have a negative effect on wine flavour (Rapp and Mandery, 1986). Experiments performed by Romano et al. (2003), using strains of $H$. uvarum and $S$. cerevisiae, showed that apiculate yeasts also produced lower amounts of higher alcohols, when compared to S. cerevisiae.

Wines produced by $S$. cerevisiae, in pure or mixed cultures, presented concentrations of 2-phenylethanol between 43.1 and $58.1 \mathrm{mg} \mathrm{l}^{-1}$
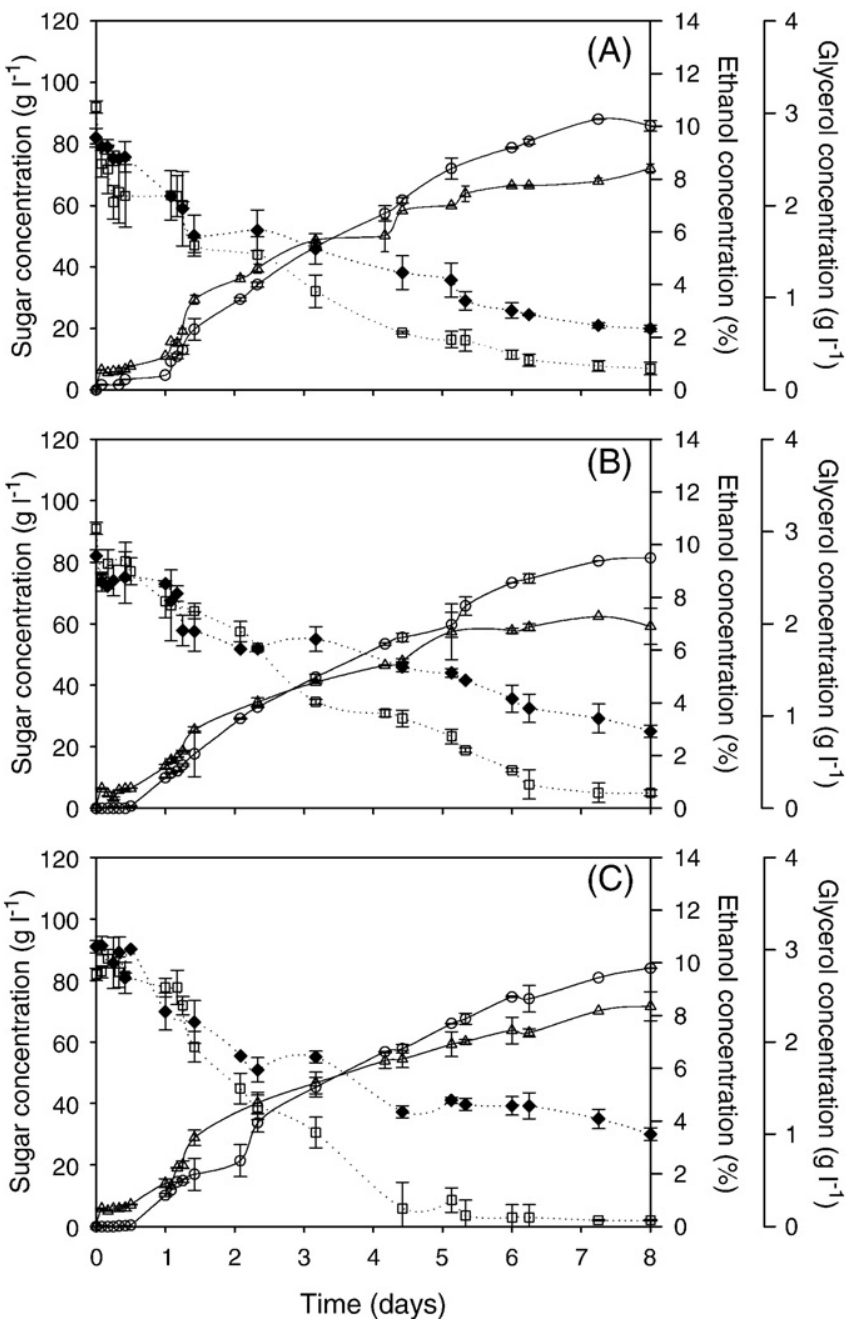

Fig. 4. Glucose $(\square)$ and fructose $(\diamond)$ utilisation, ethanol $(O)$ and glycerol $(\triangle)$ production by mixed cultures of (A) $H$. uvarum and $S$. cerevisiae, (B) $H$. guilliermondii and $S$. cerevisiae, (C) H. uvarum, H. guilliermondii and $S$. cerevisiae on grape must. Values of concentrations are the average values of results obtained from four fermentations. Vertical bars represent standard deviation. 
Table 2

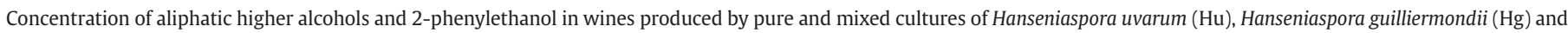
Saccharomyces cerevisiae (Sc)

\begin{tabular}{|c|c|c|c|c|c|c|c|}
\hline \multirow[t]{2}{*}{ Concentration $\left(\mathrm{mg} \mathrm{l}^{-1}\right)$} & \multicolumn{3}{|c|}{ Pure cultures } & \multicolumn{3}{|c|}{ Mixed cultures } & \multirow[t]{2}{*}{ Sig } \\
\hline & $\mathrm{Hu}$ & $\mathrm{Hg}$ & Sc & $\mathrm{Hu}-\mathrm{Sc}$ & $\mathrm{Hg}-\mathrm{Sc}$ & $\mathrm{Hu}-\mathrm{Hg}-\mathrm{Sc}$ & \\
\hline 2-Phenylethanol & $34.5(2.9)^{\mathrm{a}}$ & $32.5(5.2)^{a}$ & $58.1(8.4)^{\mathrm{bc}}$ & $56.3(5.3)^{\mathrm{bc}}$ & $43.1(3.1)^{\mathrm{abc}}$ & $55.8(4.5)^{\mathrm{c}}$ & $\dagger$ \\
\hline 1-Propanol & $13.4(1.3)^{\mathrm{a}}$ & $21.4(0.8)^{\mathrm{b}}$ & $21.3(1.0)^{\mathrm{b}}$ & $21.2(3.4)^{\mathrm{b}}$ & $21.8(3.6)^{\mathrm{b}}$ & $29.1(1.9)^{c}$ & $\dagger$ \\
\hline 3-Methyl-1-propanol & $49.5(5.8)^{\mathrm{a}}$ & $138(17)^{b}$ & $221(26)^{\mathrm{c}}$ & $172(19)^{\mathrm{bc}}$ & $123(42)^{\mathrm{b}}$ & $146(20)^{\mathrm{b}}$ & $\dagger$ \\
\hline 2-Methyl-1-butanol & $26.0(1.3)^{a}$ & $50.4(0.2)^{\mathrm{b}}$ & $127(7)^{d}$ & $125(9)^{d}$ & $102(16)^{\mathrm{c}}$ & $114(2)^{\mathrm{cd}}$ & $\dagger$ \\
\hline 3-Methyl-1-butanol & $53.7(3.8)^{\mathrm{a}}$ & $46.7(1.4)^{\mathrm{a}}$ & $205(2)^{d}$ & $186(7)^{\mathrm{cd}}$ & $159(31)^{\mathrm{bc}}$ & $147(4)^{b}$ & $\dagger$ \\
\hline Total aliphatic higher alcohols & $143(12)^{a}$ & $257(19)^{\mathrm{ab}}$ & $574(36)^{e}$ & $504(38)^{\text {de }}$ & $406(93)^{\mathrm{c}}$ & $436(28)^{\mathrm{cd}}$ & $\dagger$ \\
\hline
\end{tabular}

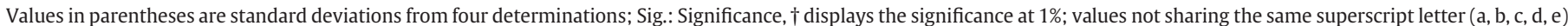
within the horizontal line are different according to the Tukey test.

(Table 2); a lower content of this compound was observed in wines produced by pure cultures of apiculate yeasts (32.5-34.5 $\left.\mathrm{mg} \mathrm{l}^{-1}\right)$. 2Phenylethanol, as well its acetate, plays a positive role in the aroma of wines, bringing fruity and flowery flavours (Rapp and Mandery, 1986). Similar results were also obtained by Rojas et al. (2003), the highest level of 2-phenylethanol $\left(82.1 \mathrm{mg} \mathrm{l}^{-1}\right)$ being found in wines produced by $S$. cerevisiae, while $H$. guilliermondii produced $14.7 \mathrm{mg} \mathrm{l}^{-1}$; however, a concentration of $29.2 \mathrm{mg} \mathrm{l}^{-1}$ was obtained in mixed cultures of S. cerevisiae and $H$. guilliermondii.

\section{Esters}

Although residual sugar is present in wines, $H$. guilliermondii produced the highest level of 2-phenylethyl acetate (a value of $8.5 \mathrm{mg} \mathrm{l}^{-1}$ was obtained in pure culture) and its presence in mixed cultures also contributed to an extensive content of this compound, 7.8-17.3 $\mathrm{mg} \mathrm{l}^{-1}$ (Fig. 5A). These values are higher than those usually found in literature, which vary from 0.01 to $4.5 \mathrm{mg} \mathrm{l}^{-1}$ (Lambrechts and Pretorius, 2000). In agreement with the results reported here, studies performed on a basal commercial medium showed that growth of $H$. guilliermondii increased the level of 2-phenylethyl acetate in both pure and mixed cultures with S. cerevisiae (Moreira et al., 2005).

The highest levels of isoamyl acetate were found in wines produced with $\mathrm{H}$. uvarum, wherever in pure $\left(5.1 \mathrm{mg} \mathrm{l}^{-1}\right.$ ) or mixed cultures (3.7$4.8 \mathrm{mg} \mathrm{l}^{-1}$ ) with S. cerevisiae (Fig. 5B). H. guilliermondii and H. uvarum were also responsible for wines with high contents of hexyl acetate (Fig. 5C). Wines produced by $S$. cerevisiae presented a low content in acetates of higher alcohols (Fig. 5A,B,C); however, pure or mixed cultures of $S$. cerevisiae produced wines with the highest level of ethyl hexanoate (Fig. 5D). Although significant differences in ethyl decanoate content of wines were observed, those variations did not correlate with the yeast strains (Fig. 5E). The concentration of ethyl octanoate in wines was also analysed, but there were no significant differences of its level $\left(0.090-0.193 \mathrm{mg} \mathrm{l}^{-1}\right.$ ) in all experiments performed (data not shown).

The acetates of higher alcohols contribute positively to wine aroma; they have an intense fruity odour of banana, acid drops and apple. The
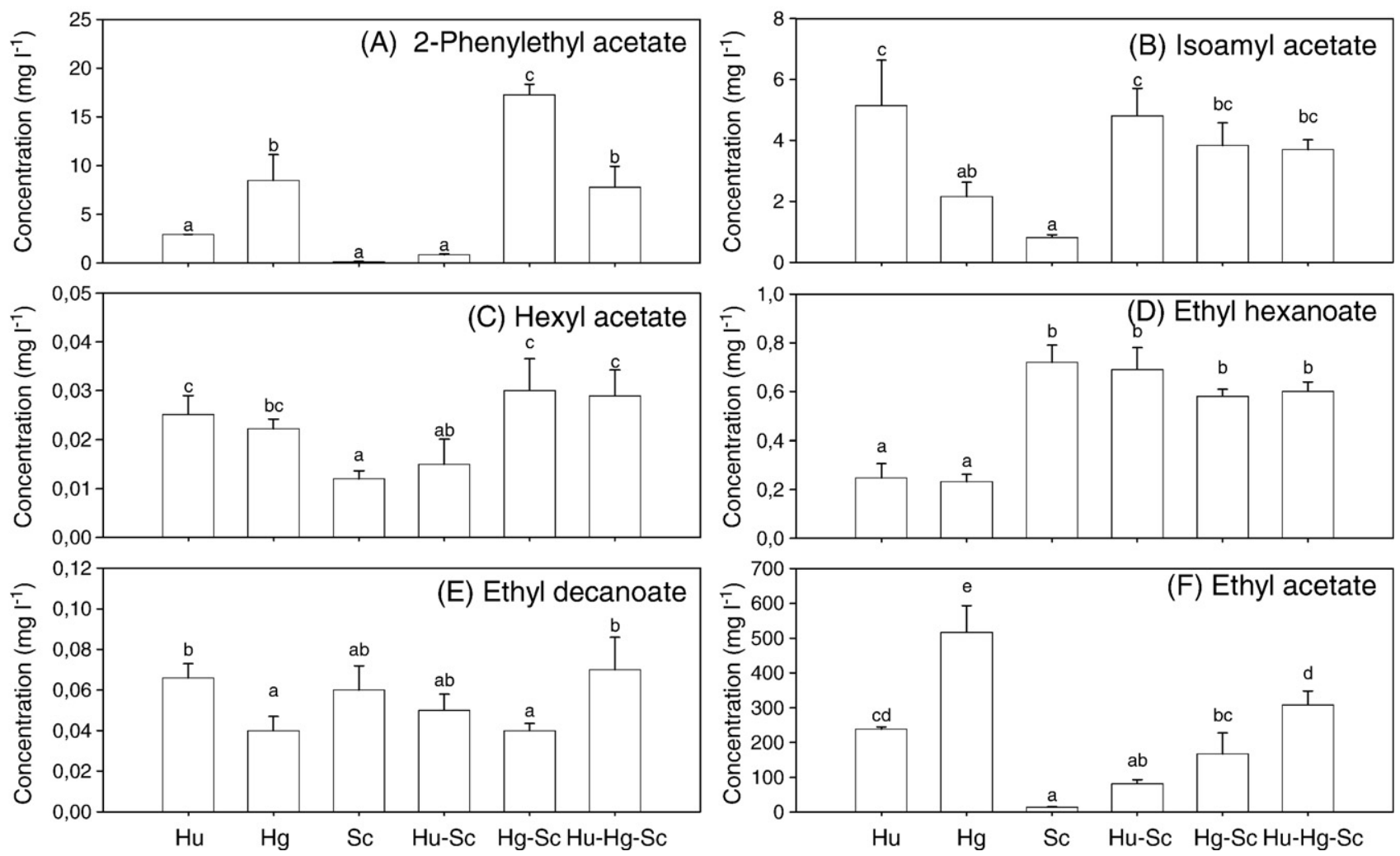

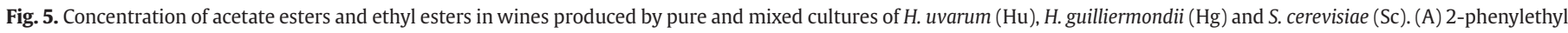

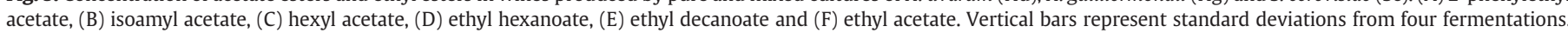
Values not sharing the same superscript letter (a, b, c, d, e) on top bar are different according to the Tukey test. 
Table 3

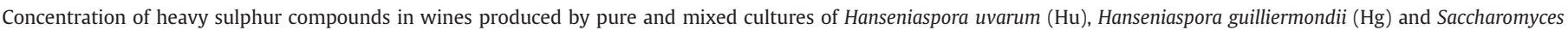
cerevisiae (Sc)

\begin{tabular}{|c|c|c|c|c|c|c|c|}
\hline \multirow[t]{2}{*}{ Concentration $\left(\mu \mathrm{g} \mathrm{l}^{-1}\right)$} & \multicolumn{3}{|l|}{ Pure cultures } & \multicolumn{3}{|l|}{ Mixed cultures } & \multirow[t]{2}{*}{ Sig } \\
\hline & $\mathrm{Hu}$ & $\mathrm{Hg}$ & Sc & $\mathrm{Hu}-\mathrm{Sc}$ & $\mathrm{Hg}-\mathrm{Sc}$ & $\mathrm{Hu}-\mathrm{Hg}-\mathrm{Sc}$ & \\
\hline Methionol & $1049(42)^{\mathrm{a}}$ & $1664(104)^{\mathrm{bc}}$ & $1882(173)^{\mathrm{bc}}$ & $1586(195)^{\mathrm{b}}$ & $2059(212)^{\mathrm{c}}$ & $1805(110)^{\mathrm{bc}}$ & $\dagger$ \\
\hline Acetic acid-3-(methylthio)propyl ester $(*)$ & $13.9(0.5)^{\mathrm{c}}$ & $5.78(1.42)^{\mathrm{b}}$ & $\mathrm{nd}^{\mathrm{a}}$ & $\mathrm{nd}^{\mathrm{a}}$ & $\mathrm{nd}^{\mathrm{a}}$ & $\mathrm{nd}^{\mathrm{a}}$ & $\dagger$ \\
\hline 3-(Ethylthio)-1-propanol & $74.2(12.0)^{\mathrm{a}}$ & $270(43)^{c}$ & $90.9(6.4)^{a}$ & $97.6(2.9)^{\mathrm{a}}$ & $186(18)^{b}$ & $123(37)^{\mathrm{ab}}$ & $\dagger$ \\
\hline 4-(Methylthio)-1-butanol & $16.4(3.1)^{a}$ & $80.2(18.8)^{b}$ & $19.2(3.9)^{\mathrm{a}}$ & $20.0(3.5)^{\mathrm{a}}$ & $24.5(0.7)^{\mathrm{a}}$ & $26.2(7.1)^{\mathrm{a}}$ & $\dagger$ \\
\hline 3-Mercapto-1-propanol & $9.02(1.91)^{\mathrm{a}}$ & $404(79)^{d}$ & $77.5(8.0)^{\mathrm{a}}$ & $84.3(15.9)^{\mathrm{ab}}$ & $282(16)^{c}$ & $191(49)^{\mathrm{bc}}$ & $\dagger$ \\
\hline cis-2-methyltetrahydro-thiophen-3-ol (*) & $6.46(1.36)^{\mathrm{a}}$ & $263(23)^{b}$ & $1.47(0.18)^{\mathrm{a}}$ & $1.93(0.05)^{\mathrm{a}}$ & $14.9(4.1)^{\mathrm{a}}$ & $16.9(4.9)^{\mathrm{a}}$ & $\dagger$ \\
\hline trans-2-methyltetrahydro-thiophen-3-ol $(*)$ & $0.609(0.024)^{\mathrm{c}}$ & $4.68(0.08)^{d}$ & $0.129(0.018)^{\mathrm{a}}$ & $0.077(0.015)^{\mathrm{a}}$ & $0.328(0.080)^{\mathrm{b}}$ & $0.434(0.122)^{\mathrm{bc}}$ & $\dagger$ \\
\hline 2-Mercaptoethanol & $480(105)^{\mathrm{b}}$ & $148(30)^{\mathrm{a}}$ & $294(75)^{\mathrm{ab}}$ & $324(62)^{\mathrm{ab}}$ & $246(12)^{\mathrm{a}}$ & $307(81)^{\mathrm{ab}}$ & $\dagger$ \\
\hline 2-(Methylthio)ethanol+2-methyltetrahydrothiophen-3-one & $596(9)^{d}$ & $21.9(0.6)^{\mathrm{a}}$ & $457(124)^{d}$ & $294(22)^{c}$ & $115(26)^{\mathrm{ab}}$ & $200(60)^{\mathrm{bc}}$ & $\dagger$ \\
\hline
\end{tabular}

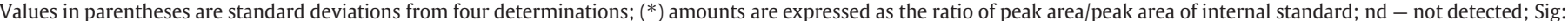
significance, ${ }^{\dagger}$ displays the significance at $1 \%$; values not sharing the same superscript letter (a, b, c, d) within the horizontal line are different according to the Tukey test.

ethyl esters of fatty acids also present pleasant odours of wax and honey (Ribéreau-Gayon et al., 2000). According to Herraiz et al. (1990), the production of ethyl esters and isoamyl acetate was significantly higher in wines produced by a pure culture of $S$. cerevisiae and the sequential inoculation of apiculate yeasts resulted in a decrease in the production of these compounds. However, experiments performed by Rojas et al. (2003) showed that, in general, S. cerevisiae produced wines with the highest content in isoamyl acetate $\left(6.9 \mathrm{mg} \mathrm{l}^{-1}\right)$ and ethyl esters, whereas $H$. guilliermondii produced the highest contents in 2phenylethyl acetate $\left(8.8 \mathrm{mg} \mathrm{l}^{-1}\right)$ and hexyl acetate $\left(0.028 \mathrm{mg} \mathrm{l}^{-1}\right)$.

Ethyl acetate is the main ester occurring in wine and possesses an unpleasant odour (acetic odour). This ester contributes significantly to defect aroma at a content of 150 to $200 \mathrm{mg} \mathrm{l}^{-1}$ (Lambrechts and Pretorius, 2000). H. guilliermondii produced the highest content in ethyl acetate $\left(516 \mathrm{mg} \mathrm{l}^{-1}\right)$; however, growth of $S$. cerevisiae in mixed cultures with apiculate yeasts led to wines with a lower content in this compound (80.9-308 $\mathrm{mg} \mathrm{l}^{-1}$ ) (Fig. 5F). The high production of ethyl acetate and acetic acid by apiculate yeasts has been widely reported (Ciani and Picciotti, 1995; Rojas et al., 2003; Plata et al., 2003; Romano et al., 2003; Ciani et al., 2006); this is the main reason why some authors exclude the utilisation of apiculate yeasts in winemaking.

\section{Heavy sulphur compounds}

According to the yeast strains used, significant differences of the amounts of sulphur compounds in the resulting wines were observed $(P<0.05)$; however, growth of apiculate yeasts may not have a negative influence on the production of heavy sulphur compounds.

As expected, methionol was present at high levels in wines (Table 3). In mixed cultures of apiculate yeasts and S. cerevisiae, wines presented amounts of methionol and acetic acid-3-(methylthio) propyl ester similar to those produced by a pure culture of $S$. cerevisiae. The lowest value of methionol $\left(1049 \mu \mathrm{g} \mathrm{l}^{-1}\right)$ was found in wines elaborated by a pure culture of $H$. uvarum. For the other wines, higher concentrations of this compound were found, varying from $1664 \mathrm{\mu g} \mathrm{l}^{-1}$ in wines produced by a pure culture of $H$. guilliermondii to $2059 \mu \mathrm{g} \mathrm{I}^{-1}$ in wines produced by a mixed culture of $H$. guilliermondii and S. cerevisiae. A pure culture of $H$. uvarum led to a wine with the highest content in acetic acid-3-(methylthio)propyl ester, whereas this compound was not detected in wines produced by a pure culture of S. cerevisiae or by mixed cultures of apiculate yeasts with S. cerevisiae. A low production of this compound was also obtained in mixed cultures of apiculate yeasts with $S$. cerevisiae grown on a basal commercial medium (Moreira et al., 2005). During fermentation, acetic acid-3-(methylthio)propyl ester is produced by the reaction of methionol with the acetic acid formed (Fig. 1). The production of acetic acid by apiculate wine yeasts has been widely studied; in general, these yeasts produce a high level of acetic acid, when compared to the amount of ethanol synthesised (Ciani and Picciotti, 1995; Ciani and Maccarelli, 1998; Zohre and Erten, 2002).
A pure culture of $H$. guilliermondii led to wines with the lowest amounts of 2-mercaptoethanol and the highest contents in 3(ethylthio)-1-propanol, 4-(methylthio)-1-butanol, 3-mercapto-1-propanol, cis- and trans-2-methyltetrahydro-thiophen-3-ol, when compared to wines produced by pure cultures of $H$. uvarum and $S$. cerevisiae (Table 3). The highest content of 2-mercaptoethanol was obtained in wine produced by a pure culture of H. uvarum. However, when apiculate yeasts were used in mixed cultures with $S$. cerevisiae, wines showed amounts of 4-(methylthio)-1-butanol, 2-mercaptoethanol and cis-2-methyltetrahydro-thiophen-3-ol similar to those produced by a pure culture of $S$. cerevisiae. The lowest amounts of 2(methylthio)ethanol+2-methyltetrahydrothiophen-3-one were also obtained in wines produced by a pure culture of $H$. guilliermondii. In mixed cultures of $H$. uvarum and $S$. cerevisiae, a decrease in the production of these compounds was observed, when compared to wines produced from pure cultures of the same yeasts.

To our knowledge, analysis of heavy sulphur compounds produced by apiculate yeasts grown in grape musts was never reported before. A previous study on apiculate yeasts showed the production of methionol, 3-methylthio-propionic acid, acetic acid-3-(methylthio) propyl ester and 2-methyltetrahydrothiophen-3-one, when yeasts were grown in a basal commercial medium (Moreira et al., 2005); in these conditions a lower metabolic activity than in grape musts occurs, and, consequently, a much lower production of secondary fermentation products was observed. Although reports on esters and higher alcohols production by apiculate yeasts are available in literature, controversial results were reported. Data obtained in the present work confirm that apiculate yeasts are lower producers of higher alcohols than $S$. cerevisiae and are able to synthesise higher amounts of some desirable esters, like 2-phenylethyl acetate and isoamyl acetate.

\section{Conclusions}

Growth of apiculate yeasts during the first days of grape must fermentation cannot be neglected. Results obtained in this work suggest the potential of apiculate yeasts in producing desirable compounds, such as esters, in order to obtain wines with characteristic aroma and/or flavour. Moreover, growth of apiculate yeasts in mixed cultures with S. cerevisiae may not enhance the production of higher alcohols and undesirable compounds such as heavy sulphur compounds. H. guilliermondii led to wines with the highest level of 2phenylethyl acetate, whereas $H$. uvarum increased the content of isoamyl acetate in wines. Growth of apiculate yeasts in mixed cultures with $S$. cerevisiae reduced the total concentration of higher alcohols in wines, when compared to those produced by a pure culture of $S$. cerevisiae. The contents of sulphur compounds in wines also varied according to the yeast strain used. In general, when apiculate yeasts were grown in mixed cultures with $S$. cerevisiae, wines presented amounts of heavy sulphur compounds similar to those produced by a 
pure culture of S. cerevisiae. Pure cultures of apiculate yeasts produced high amounts of ethyl acetate, an undesirable compound; however, the level of this compound in wines decreased in mixed cultures of apiculate yeasts and S. cerevisiae. The ethyl acetate content of wines produced by apiculate yeasts requires further studies to prevent its formation during winemaking.

In addition to the winemaking industry, the data presented in this work are also pertinent to distillate industry which employs wine as starting material. In order to select the appropriate apiculate yeast species for vinification, the use of mixed cultures should be studied further, combined with vinification technology and sensory evaluation of resulting wines.

\section{Acknowledgements}

The authors gratefully acknowledge the financial support from FCT (via a Ph.D. fellowship Ref. ${ }^{a}$ PRAXIS XXI/BD/5062/95) and FSE (III Quadro Comunitário de Apoio) and PAMAF (INIA, Project 2025).

\section{References}

Anocibar Beloqui, A., Bertrand, A., 1995. Study of sulfur compounds in wine: preliminary results. Italian Journal of Food Science 3, 279-288.

Ciani, M., Maccarelli, F., 1998. Oenological properties of non-Saccharomyces yeasts associated with wine-making. World Journal of Microbiology and Biotechnology 14, 199-203.

Ciani, M., Fatichenti, F., 1999. Selective sugar consumption by apiculate yeasts. Letters in Applied Microbiology 28, 203-206.

Ciani, M., Picciotti, G., 1995. The growth kinetics and fermentation behaviour of some non-Saccharomyces yeasts associated with wine-making. Biotechnology Letters 17, 1247-1250.

Ciani, M., Beco, L., Comitini, F., 2006. Fermentation behaviour and metabolic interactions of multistarter wine yeast fermentations. International Journal of Food Microbiology 108, 239-245.

Cocolin, L., Bisson, L.F., Mills, D.A., 2000. Direct profiling of the yeast dynamics in wine fermentations. FEMS Microbiology Letters 189, 81-87.

Constantí, M., Poblet, M., Arola, L., Mas, A., Guillamón, J., 1997. Analysis of yeast populations during alcoholic fermentation in a newly established winery. American Journal of Enology and Viticulture 48, 339-344.

Darriet, P., Lavigne-Cruege, V., Tominaga, T., 1999. A Paradox: the Volatile Sulphur Compounds Responsible for both Defects and Qualities in Wines. Vigne et Vin Publications International, Bordeaux, France, p. 127.

Egli, C.M., Edinger, W.D., Mitrakul, C.M., Henick-Kling, T., 1998. Dynamics of indigenous and inoculated yeast populations and their effect on the sensory character of Riesling and Chardonnay wines. Journal of Applied Microbiology 85, 779-789.

Fleet, G.H., 2003. Yeast interactions and wine flavour. International Journal of Food Microbiology 86, 11-22.

Fleet, G.H., Heard, G.M., 1993. Yeasts-growth during fermentation. In: Fleet, G.H. (Ed.), Wine Microbiology and Biotechnology. Harwood Academic Publishers, Chur, Switzerland, pp. 27-55.

Fleet, G.H., Lafon-Lafourcade, S., Ribéreau-Gayon, P., 1984. Evolution of yeasts and lactic acid bacteria during fermentation and storage of Bordeaux wines. Applied and Environmental Microbiology 48, 1034-1038.

Gil, J., Mateo, J., Jiménez, M., Pastor, A., Huerta, T., 1996. Aroma compounds in wine as influenced by apiculate yeasts. Journal of Food Science 61, 1247-1266.

Goto, S., 1980. Changes in the wild yeast flora of sulphited grape musts. Journal of Institute of Enology and Viticulture Yamanashi University 15, 29-32.

Henick-Kling, T., Edinger, W., Daniel, P., Monk, P., 1998. Selective effects of sulphur dioxide and yeast starter culture addition on indigenous yeast population and sensory characteristics of wine. Journal of Applied Microbiology 84, 865-876.

Herraiz, T., Reglero, G., Herraiz, M., Martín-Alvarez, P., Cabezudo, M.D., 1990. The influence of the yeast and type of culture on the volatile composition of wines fermented without sulfur dioxide. American Journal of Enology and Viticulture 41, 313-318.
Kunkee, R.E., 1984. Selection and modification of yeasts and lactic acid bacteria for wine fermentation. Food Microbiology 1, 315-332.

Lambrechts, M.G., Pretorius, I.S., 2000. Yeast and its importance to wine aroma. A review. South African Journal of Enology and Viticulture 21, 97-129.

Landaud, S., Helinck, S., Bonnarme, P., 2008. Formation of volatile sulphur compounds and metabolism of methionine and other sulphur compounds in fermented food Applied Microbiology and Biotechnology 77, 1191-1205.

Lavigne, V., 1996. Recherches sur les composés soufrés volatils formés par la levure au cours de la vinification et l'élevage des vins blancs sec, Ph.D. thesis, University of Bordeaux II, Bordeaux, France.

Lema, C., Garcia-Jares, C., Orriols, I., Ângulo, L., 1996. Contribution of Saccharomyces and non-Saccharomyces populations to the production of some components of Albariño wine aroma. American Journal of Enology and Viticulture 47, 206-216.

Martinez, J., Millan, C., Ortega, J.M., 1989. Growth of natural flora during the fermentation of inoculated musts from 'Pedro Ximenez' grapes. South African Journal of Enology and Viticulture 10, 31-35.

Mestres, M., Busto, O., Guasch, J., 2000. Analysis of organic sulfur compounds in wine aroma. Journal of Chromatography A 881, 569-581.

Moreira, N., Guedes de Pinho, P., Vasconcelos, I., 2004. Method for analysis of heavy sulphur compounds using gas chromatography with flame photometric detection. Analytica Chimica Acta 513, 183-189.

Moreira, N., Mendes, F., Hogg, T., Vasconcelos, I., 2005. Alcohols, esters and heavy sulphur compounds production by pure and mixed cultures of apiculate wine yeasts. International Journal of Food Microbiology 103, 285-294.

Nissen, P., Arneborg, N., 2003. Characterization of early deaths of non-Saccharomyces yeasts in mixed cultures with Saccharomyces cerevisiae. Archives of Microbiology 5 , 65-71.

Nissen, P., Nielsen, D., Arneborg, N., 2003. Viable Saccharomyces cerevisiae cells at high concentrations cause early growth arrest of non-Saccharomyces yeasts in mixed cultures by cell-cell contact-mediated mechanism. Yeast 20, 331-341.

Pérez-Nevado, F., Albergaria, H., Hogg, T., Gírio, F., 2006. Cellular death of two nonSaccharomyces wine-related yeasts during mixed fermentations with Saccharomyces cerevisiae. International Journal of Food Microbiology 108, 336-345.

Plata, C., Millán, C., Mauricio, J.C., Ortega, J.M., 2003. Formation of ethyl acetate and isoamyl acetate by various species of wine yeasts. Food Microbiology 20, 217-224

Rapp, A., Mandery, H., 1986. Wine aroma. Experientia 42, 873-884.

Rapp, A., Güntert, M., Almy, J., 1985. Identification and significance of several sulphurcontaining compounds in wine. American Journal of Enology and Viticulture 36, 219-221.

Rauhut, D., 1993. Production of sulfur compounds. In: Fleet, G.H. (Ed.), Wine Microbiology and Biotechnology. Harwood Academic Publishers, Chur, Switzerland, pp. 183-242.

Ribéreau-Gayon, P., Glories, Y., Manjean, A., Dubourdieu, D., 2000. Handbook of Enology. The Chemistry of Wine Stabilization and Treatments, vol. 2. John Wiley \& Sons Ltd, Chichester.

Rojas, V., Gil, J., Piñaga, F., Manzanares, P., 2003. Acetate ester formation in wine by mixed cultures in laboratory fermentations. International Journal of Food Microbiology 86, 181-188.

Romano, P., Fiore, C., Paraggio, M., Caruso, M., Capece, A., 2003. Function of yeasts species and strains in wine flavour. International Journal of Food Microbiology 86, 169-180.

Schütz, M., Gafner, J., 1993. Analysis of yeast diversity during spontaneous and induced alcoholic fermentations. Journal of Applied Bacteriology 75, 551-558.

Swiegers, J.H., Pretorius, I.S., 2007. Modulation of volatile sulphur compounds by wine yeast. Applied Microbiology and Biotechnology 74, 954-960.

Swiegers, J.H., Bartowsky, E.J., Henschke, P.A., Pretorius, I.S., 2005. Yeast and bacterial modulation of wine aroma and flavour. The Australian Journal of Grape and Wine Research 11, 139-173.

Xufre, A., Albergaria, H., Inácio, J., Spencer-Martins, I., Gírio, F., 2006. Application of fluorescence in situ hybridisation (FISH) to the analysis of yeast population dynamics in winery and laboratory grape must fermentations. International Journal of Food Microbiology 108, 376-384.

Wang, X.D., Bohlscheid, J.C., Edwards, C.G., 2003. Fermentative activity and production of volatile compounds by Saccharomyces grown in synthetic grape juice media deficient in assimilable nitrogen and/or pantothenic acid. Journal of Applied Microbiology 94, 349-359.

Zohre, D.E., Erten, H., 2002. The influence of Kloeckera apiculata and Candida pulcherrima yeasts on wine fermentation. Process Biochemistry 38, 319-324. 